\title{
Host-Specific Toxin Production by Rhizoctonia solani, the Rice Sheath Blight Pathogen
}

\author{
P. Vidhyasekaran, T. Ruby Ponmalar, R. Samiyappan, R. Velazhahan, R. Vimala, \\ A. Ramanathan, V. Paranidharan, and S. Muthukrishnan
}

First, second, third, fourth, fifth, sixth, and seventh authors: Department of Plant Pathology, Tamil Nadu Agricultural University, Coimbatore 641 003, India; and eighth author: Department of Biochemistry, Kansas State University, Manhattan 66506.

Accepted for publication 27 August 1997.

\begin{abstract}
Vidhyasekaran, P., Ruby Ponmalar, T., Samiyappan, R., Velazhahan, R., Vimala, R., Ramanathan, A., Paranidharan, V., and Muthukrishnan, S. 1997. Host-specific toxin production by Rhizoctonia solani, the rice sheath blight pathogen. Phytopathology 87:1258-1263.

Rhizoctonia solani, the rice sheath blight pathogen, produces a toxin that reproduces all symptoms of the disease. The toxin has been partially puri-

fied and it was found to be a carbohydrate containing glucose, mannose, $\mathrm{N}$ acetylgalactosamine, and $N$-acetylglucosamine. The toxin was also detected in infected leaves. Highly virulent isolates produced more toxin than less virulent isolates. Several $R$. solani isolates from rice and one each from cotton and tomato produced a similar toxin. All rice cultivars tested were susceptible to the pathogen and sensitive to the toxin. Host specificity of the toxin has been demonstrated using hosts and nonhosts of the pathogen.
\end{abstract}

Rice sheath blight caused by Rhizoctonia solani Kühn is a serious disease in all rice-growing countries (26). The symptoms of the disease include greenish gray elliptical or oval-shaped spots with yellow margins mostly found on leaf sheaths, but, at times, leaf blades are also infected. The symptoms of the disease suggest possible involvement of phytotoxin in lesion symptom development. However, no toxins involved in symptom development have been isolated from the rice sheath blight pathogen, although toxic metabolites that inhibit seed germination and seedling growth and cause necrosis have been isolated from $R$. solani isolates from different hosts $(1,5,7,9,12-14,17,21-24,28,29)$. We report isolation of a hostspecific toxin from the rice sheath blight pathogen that induced characteristic symptoms of the disease only on hosts of the pathogen.

\section{MATERIALS AND METHODS}

Fungal isolates and pathogenicity. $R$. solani was isolated from sheath blight lesions found in rice cultivars grown in different regions of Tamil Nadu, India. Twelve isolates of the fungus were obtained and maintained on potato dextrose agar (PDA) (potato, $250 \mathrm{~g}$; dextrose, $20 \mathrm{~g}$; agar, $15 \mathrm{~g}$; and distilled water, 1,000 ml; $\mathrm{pH} 7.0$ ) medium. To test their virulence, the fungal isolates were grown on rice hull-rice grain medium (20). The medium contained $300 \mathrm{~g}$ of rice hull, $100 \mathrm{~g}$ of rice grain, and $200 \mathrm{ml}$ of water. The mixture was placed in a 500-ml Erlenmeyer conical flask and autoclaved at $121^{\circ} \mathrm{C}$ for $20 \mathrm{~min}$. The following day, a 4-mm agar disk from the periphery of a 5-day-old culture of $R$. solani grown on PDA in a petri dish was transferred aseptically to the mixture and incubated for 2 weeks at room temperature $\left(25 \pm 2^{\circ} \mathrm{C}\right)$.

Rice cultivar IR 50 was grown under greenhouse conditions. The temperature inside the greenhouse ranged from 20 to $28^{\circ} \mathrm{C}$ and the humidity ranged from 60 to $90 \%$ relative humidity during the experimental period. Rice seeds were soaked in water for $24 \mathrm{~h}$, and then the excess water was drained. The seeds were placed in a cloth

Corresponding author: P. Vidhyasekaran

E-mail address: tnau/coimbatore@dartmail.dartnet.com

Publication no. P-1997-1027-01R

(C) 1997 The American Phytopathological Society bag and allowed to sprout for $24 \mathrm{~h}$ in darkness. The sprouted seeds were sown (four seeds per pot) in 30-cm-diameter mud pots containing $10 \mathrm{~kg}$ of clay loam soil. The soil was fertilized with $150 \mathrm{mg}$ of nitrogen in the form of urea, $50 \mathrm{mg}$ of phosphorus in the form of superphosphate, and $50 \mathrm{mg}$ of potassium in the form of potassium sulfate per kilogram of soil at the time of sowing. The pots were watered up to a $6 \mathrm{~cm}$ depth, and irrigation was repeated when the ponded water disappeared from the soil surface. The pots were arranged $15 \mathrm{~cm}$ apart on greenhouse benches.

When the plants were 45 days old, the rice hull-rice grain inoculum ( $1 \mathrm{~g}$ ) of $R$. solani was placed in between the stem and the basal leaf sheath of each tiller of the hill (10 to 15 tillers per hill) at about 3 to $4 \mathrm{~cm}$ above the water line. The fungus infected leaf sheaths at the base of culms, producing oblong, gray-green, watersoaked spots. The fungus spread to the upper part of the foliage by producing several lesions on entire tillers from the water line to the flag leaf. The disease intensity was assessed at 90 days after sowing by measuring the height of each tiller (from base of the culm to tip of the flag leaf) and the lesion height (from base of the culm to the highest point at which the lesion was seen in a tiller). The relative lesion height (RLH) in each tiller was calculated by using the formula described by Sharma et al. (27).

$$
\text { Relative lesion height } \%=\frac{\text { Highest point a lesion is seen }(\mathrm{cm})}{\text { Plant height }(\mathrm{cm})} \times 100
$$

To test the virulence of $R$. solani isolates, each isolate was inoculated on 20 plants in five pots (four plants per pot). All tillers of all plants were scored for RLH. When there was no lesion in a tiller, the disease intensity in that tiller was scored as 0 . The disease intensity index was obtained by totaling the RLH percentage of each tiller and calculating the mean value per tiller. Four isolates $\left(\mathrm{I}_{1}, \mathrm{I}_{2}, \mathrm{I}_{3}\right.$, and $\left.\mathrm{I}_{7}\right)$ with varying degrees of virulence were selected for further studies. Two $R$. solani isolates were also obtained from root rot-affected cotton and tomato plants grown in Coimbatore, and these were also used in the current studies. The isolates from rice, cotton, and tomato appeared to belong to different anastomosis groups, as the hyphae of an isolate from a crop did not show any anastomosis with hyphae of isolates from other crops when sclerotia of two different isolates were grown on plain 
agar medium on a glass slide. Anastomosis between the four rice isolates was observed.

Isolation of toxin. Toxin production by the most virulent rice isolate of $R$. solani $\left(\mathrm{I}_{1}\right)$ was assessed. Erlenmeyer conical flasks $(250 \mathrm{ml})$ containing $50 \mathrm{ml}$ of Richard's medium (50 g of sucrose, $10 \mathrm{~g}$ of potassium nitrate, $5 \mathrm{~g}$ of potassium dihydrogen phosphate, $2.5 \mathrm{~g}$ of magnesium sulfate, $0.02 \mathrm{~g}$ of ferric chloride, and $1,000 \mathrm{ml}$ of distilled water, $\mathrm{pH}$ 7.0) were inoculated with a 4-mm disc of mycelia grown in PDA medium. After 15 days of growth under stationary conditions at laboratory temperature $\left(25 \pm 2^{\circ} \mathrm{C}\right)$, the culture fluid was obtained by filtration through three layers of cheesecloth. Richard's medium not inoculated with the fungus served as a control. The culture filtrates were concentrated in vacuo at $50^{\circ} \mathrm{C}$ to $10 \%$ of their original volume. An equal volume of methanol was added, and the solution was stored overnight at $5^{\circ} \mathrm{C}$. Precipitates were removed by filtration through Whatman No. 1 filter paper (Whatman International, Ltd., Maidstone, England). The precipitates were then dissolved in water $(10 \mathrm{ml})$, and their ability to induce disease symptoms was assessed by the detached leaf sheath bioassay by applying $50 \mu \mathrm{l}$ of the preparation and by electrolyte leakage bioassay by infiltrating $50 \mu \mathrm{l}$ of the preparation. After removal of the precipitate by filtration, the filtrate containing methanol and water was evaporated to dryness in vacuo at $40^{\circ} \mathrm{C}$, dissolved in $10 \mathrm{ml}$ of water, and bioassayed as described above. This water preparation was treated with activated charcoal at $3 \% \mathrm{wt} / \mathrm{vol}$, cooled to $4^{\circ} \mathrm{C}$, stirred for $12 \mathrm{~h}$, and filtered through Whatman No. 1 filter paper. The filtrate, after charcoal treatment, was evaporated to dryness, dissolved in $10 \mathrm{ml}$ of water, and bioassayed as above. The activated charcoal remaining in the filter paper was washed with $100 \mathrm{ml}$ of methanol and collected in a beaker. The methanol was evaporated in vacuo at $40^{\circ} \mathrm{C}$ using Büchi Rotavapor (Büchi Laboratoriums-Technik AG, Flawil, Switzerland). The residue was dissolved in $10 \mathrm{ml}$ of water and bioassayed as above.

This latter preparation did not show any toxicity and hence was discarded. Only the water fraction after the removal of activated charcoal by filtration through Whatman No. 1 filter paper showed toxicity. This fraction was partitioned with three volumes of ethylacetate, chloroform, hexane, carbon tetrachloride, or petroleum ether using a separating funnel. Both water and solvent fractions were evaporated to dryness in vacuo separately. The residues were dissolved in $10 \mathrm{ml}$ of water, and the ability of the individual fractions to induce disease symptoms was assessed by the detached leaf sheath and by electrolyte leakage bioassays using $50 \mu \mathrm{l}$ of the preparation. All the detached leaf sheath bioassays were done with 25 leaf sheath samples. The electrolyte leakage bioassays were done with six replications, and the data were analyzed by Duncan's multiple range test (DMRT). These experiments were repeated three times with similar results.

Detached leaf bioassay. Leaf sheaths of 60-day-old rice plants (cultivar IR 50) were detached and cut into $4-\mathrm{cm}$ pieces. Each leaf sheath was placed on a glass slide and its ends were fixed with gum tape so the leaf sheath wouldn't curl. An injury was made with the tip of a ballpoint pen. The slide was kept inside a petri dish lined with wet blotting paper. The test toxin sample was placed on a 4-mm-diameter filter paper disk that was placed on the injured leaf sheath section. The petri dishes were incubated under laboratory conditions $\left(25 \pm 2{ }^{\circ} \mathrm{C} ; 12 \mathrm{~h}\right.$ of light and $12 \mathrm{~h}$ of darkness). After 5 days of incubation, symptom development was assessed. The intensity of the symptoms was graded into four categories based on the leaf area affected: $1=1$ to $10 \%, 2=11$ to $25 \% ; 3=26$ to $50 \%$, and $4=$ more than $50 \%$ affected leaf sheath area. Twenty-five leaf sheaths were scored for symptom development.

Electrolyte leakage. Leaf sheaths of 60-day-old rice plants were used for the bioassay. The leaf sheaths were cut into small pieces ( $1 \mathrm{~cm}$ long and $5 \mathrm{~mm}$ wide) and rinsed; random samples $(100 \mathrm{mg}$ ) were enclosed in washed cheesecloth and placed in scintillating vials. The leaf sheath sections were infiltrated with the toxin samples $(50 \mu \mathrm{l})$ in vacuo for $30 \mathrm{~min}$. The leaf sheath sections were then rinsed with water, and $4 \mathrm{ml}$ of glass-distilled water was placed in each vial and incubated on a reciprocal shaker (100 strokes/ $\mathrm{min})$ at laboratory temperature. Conductances of ambient solutions were measured at 0 and $10 \mathrm{~min}$ after infiltration with a Orion model 120 conductivity meter (Orion Research, Inc., Boston). Leaf sheath samples infiltrated with water or noninoculated Richard's medium served as a control (33). Six replications were maintained.

Purification of toxin. The toxin in the culture filtrate was partially purified, and the effectiveness of each step in increasing biological activity of the toxin was assessed. Ten liters of the culture filtrate was obtained by growing the fungus for 15 days in $200250-\mathrm{ml}$ Erlenmeyer conical flasks, each containing $50 \mathrm{ml}$ of Richard's medium. The culture filtrates were evaporated to dryness in vacuo at $40^{\circ} \mathrm{C}$ using Buchi Rotavapor. The residues were weighed. Serial dilutions of a known quantity of the residues were made in water, and the dilution end point of the toxin activity was assessed by the detached leaf sheath bioassay. The residues from the culture filtrates were dissolved in $100 \mathrm{ml}$ of water, an equal volume of methanol was added, and the solution was stored overnight at $5^{\circ} \mathrm{C}$. The precipitates were removed by filtration through Whatman No. 1 filter paper. The precipitates did not show any toxicity and were hence discarded. The filtrate was evaporated to dryness and weighed. Serial dilutions of the residue were made in water, and the dilution end point of the toxin activity was assessed by the detached leaf bioassay. The residue was then dissolved in $100 \mathrm{ml}$ of water, treated with activated charcoal $3 \% \mathrm{wt} / \mathrm{vol}$, cooled to $4^{\circ} \mathrm{C}$, stirred for $12 \mathrm{~h}$, and filtered through Whatman No. 1 filter paper. When the precipitated charcoal was washed with water, no toxicity could be observed in the eluted water and hence it was discarded. The filtrate obtained after charcoal treatment was evaporated to dryness in vacuo at $40^{\circ} \mathrm{C}$. The residue was weighed, and the minimum concentration of the residue required to induce symptoms was assessed by the dilution end point assay.

The residue was then dissolved in $100 \mathrm{ml}$ of water and partitioned with three volumes of ethyl acetate. The water fraction was evaporated to dryness in vacuo at $40^{\circ} \mathrm{C}$ and weighed. The dilution end point assay was used to assess the required minimum concentration of the residue to induce symptoms.

Sephadex G-75 (Sigma Chemical Co., St. Louis) was allowed to swell for $24 \mathrm{~h}$ at $5^{\circ} \mathrm{C}$ in distilled water and packed into a column. The Sephadex bed $(1.5 \times 90-\mathrm{cm}$ column, $70-\mathrm{cm}$ bed height $)$ was washed with $500 \mathrm{ml}$ of distilled water before use. The residue dissolved in $2 \mathrm{ml}$ of water was placed on top of the column and eluted with distilled water. Elution was carried out at the rate of $0.25 \mathrm{ml}$ per min using Bio-Rad automated econosystem (Bio-Rad Laboratories, Hercules, CA). Five-milliliter fractions were collected, and toxicity of the fractions was assessed by detached leaf sheath bioassay by applying $50 \mu \mathrm{l}$ of each fraction. The fractions that induced symptoms were all pooled, evaporated to dryness in vacuo at $40^{\circ} \mathrm{C}$, weighed, and redissolved in $5 \mathrm{ml}$ of water. It was again passed through the Sephadex column, and active fractions were collected and evaporated to dryness in vacuo at $40^{\circ} \mathrm{C}$. The minimum concentration of the residue required to induce symptoms was assessed by the dilution end point assay. No significant activity was obtained when biologically inactive fractions from each step were pooled and concentrated. These experiments were repeated once with similar results.

The toxin fraction collected from the column was dissolved in water or methanol, and the UV absorption spectra of the toxin was recorded using a Beckman DU-64 spectrophotometer (Beckman Instruments, Inc., Fullerton, CA). The partially purified toxin, after passing through the Sephadex column, was used in all further studies.

Characterization of toxin. The partially purified toxin was tested for the presence of phenylacetic acid derivatives by the method described by Iacobellis and DeVay (12). The toxin sample was dissolved in methanol, spotted on thin-layer chromatography plates, and developed with a mixture of chloroform/ethanol/acetic acid 
(80:20:0.5, vol/vol). For reference, authentic phenylacetic acid derivatives were used. The developed plates were sprayed with a $0.1 \%$ solution of 2,6-dichlorophenol-indo-phenol in 95\% ethanol. Another set of developed plates were sprayed with Folin-Ciocalteau reagent (Sigma Chemical Co.) with water (1:1), followed by spraying $20 \% \mathrm{Na}_{2} \mathrm{Co}_{3}$ to assess the presence of any phenolic compound.

The partially purified toxin was assayed for carbohydrate by the anthrone method (3), with glucose as a standard. Protein was assayed by the method of Bradford (6) using bovine serum albumin as a standard. Since the toxin fraction contained both carbohydrate and protein, the toxin-active moiety of the glycoprotein was assessed by treating the toxin with $\mathrm{NaIO}_{4}$, which oxidizes or cleaves polysaccharides, and with proteinase $\mathrm{K}$, which digests proteins (8). One milliliter of the toxin preparation $(50 \mu \mathrm{g} / \mathrm{ml})$ was treated with $1 \mathrm{ml}$ of $20 \mathrm{mM} \mathrm{NaIO}$ and incubated for $22 \mathrm{~h}$ at $5^{\circ} \mathrm{C}$ in darkness. The solution was reduced to dryness in vacuo and redissolved in $1 \mathrm{ml}$ of distilled water. The toxicity of the preparation was assessed by the detached leaf sheath bioassay. To test the effect of proteinase treatment, $1 \mathrm{ml}$ of the toxin fraction $(50 \mu \mathrm{g} / \mathrm{ml})$ was treated with $1 \mathrm{ml}$ of proteinase K $\left(0.2 \mathrm{mg} \mathrm{ml}^{-1}\right.$, Sigma Chemical Co., St.

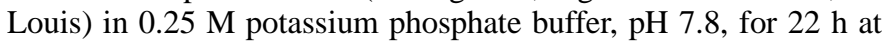
$37^{\circ} \mathrm{C}$. The solution was reduced to dryness in vacuo and redissolved in $1 \mathrm{ml}$ of sterile distilled water (8). The toxicity of this preparation was assessed by the detached leaf bioassay. For all the assays, sterile distilled water and the toxin fraction treatment served as controls. The analyses were made with three independent samples, and the experiment was repeated once with similar results.

Since the toxicity was only detected in the carbohydrate fraction, the carbohydrate composition was determined at the Experimental Station Chemical Laboratories, University of Missouri, Columbia. The toxin sample was hydrolyzed to liberate carbohydrate moieties, and sugars were reduced and derivatized to alditol or hexosaminitol acetates, which were separated by gas-liquid chromatography and quantified by mass spectrometry $(18,19)$.

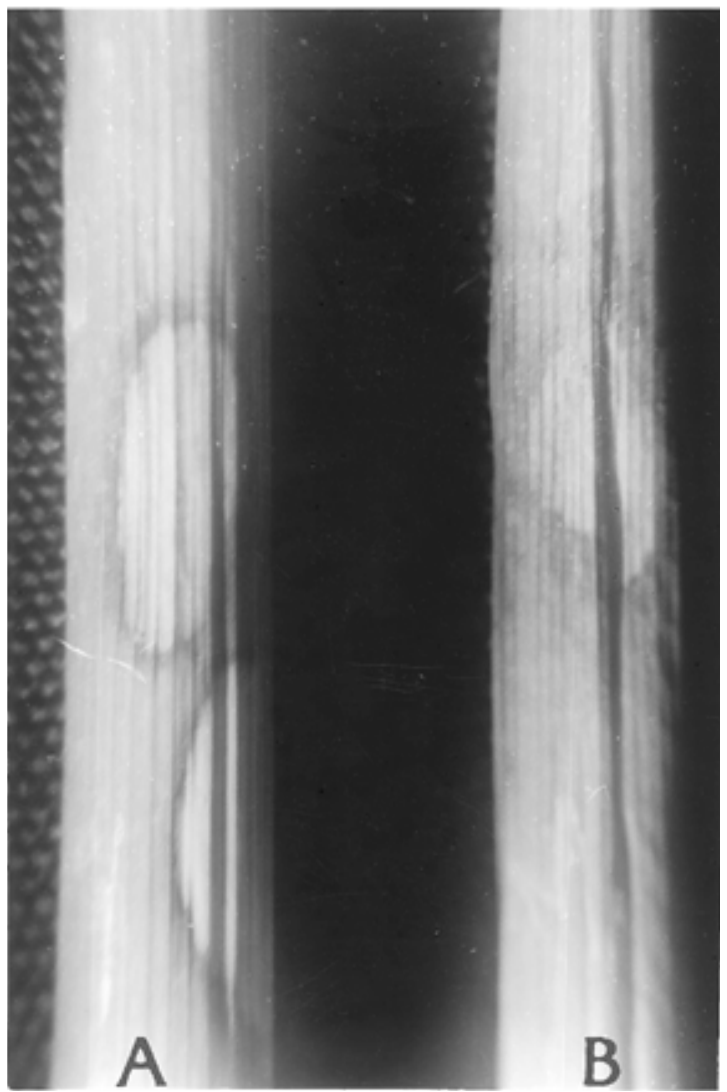

Fig. 1. Symptoms produced $\mathbf{A}$, by Rhizoctonia solani toxin and $\mathbf{B}$, by infection on rice leaf sheaths.
Isolation of toxin produced in vivo. Rice cultivar IR 50 was grown under greenhouse conditions and inoculated with the rice sheath blight pathogen $R$. solani isolate $\mathrm{I}_{1}$ at 45 days after sowing as described earlier. The infected leaf sheath samples $(1 \mathrm{~kg})$ showing characteristic lesions were collected and cut into small pieces. Noninoculated, healthy leaf sheath samples were used as a control. Both the leaf sheath samples were extracted with methanol $(1,000 \mathrm{ml})$ by heating at $65^{\circ} \mathrm{C}$ in a reflux condenser for $8 \mathrm{~h}$, cooled, and incubated at $4^{\circ} \mathrm{C}$ overnight. The methanol extracts were filtered through three layers of cheesecloth and then through Whatman No. 1 filter paper. The filtrate was evaporated to dryness in vacuo at $40^{\circ} \mathrm{C}$. The residue was dissolved in $100 \mathrm{ml}$ of water and partitioned with three volumes of ethyl acetate. The water fraction was evaporated to dryness in vacuo at $40^{\circ} \mathrm{C}$, dissolved in $2 \mathrm{ml}$ of water, placed on top of a Sephadex G-75 column, and eluted with distilled water. The toxicity of fractions was assessed by detached leaf bioassay. UV absorption spectra of the toxin fraction was recorded using a Beckman DU-64 spectrophotometer.

Relationship between virulence and toxin production. Four isolates of $R$. solani obtained from rice, an isolate from cotton, and an isolate from tomato were tested for their virulence in causing sheath blight in rice under greenhouse conditions as described earlier. There were four replications with five plants in each pot. The experiment was repeated once, and the data presented are the mean of two independent experiments. The data were statistically analyzed by DMRT.

All six isolates were grown in Richard's medium in 20 250-ml Erlenmeyer conical flasks, each containing $50 \mathrm{ml}$ of the medium. After 15 days of growth, the culture fluid was obtained by filtration through three layers of cheesecloth. The culture filtrates were concentrated in vacuo at $50^{\circ} \mathrm{C}$ to $10 \%$ of their original volume. An equal volume of methanol was added, and the solution was stored overnight at $5^{\circ} \mathrm{C}$. Precipitates were removed by filtration through Whatman No. 1 filter paper. The filtrate was evaporated to dryness in vacuo at $40^{\circ} \mathrm{C}$. The residue was weighed and then dissolved in $100 \mathrm{ml}$ of water. This preparation was used as crude toxin. The activity of the toxin produced by each isolate was assessed by detached leaf sheath bioassay, by finding out dilution end point of the crude toxin, and by electrolyte leakage bioassay. The amount

TABLE 1. Characteristics of crude toxin isolated from culture filtrates of Rhizoctonia solani

\begin{tabular}{|c|c|c|c|}
\hline Treatment & Fraction & $\begin{array}{c}\text { Electrolyte } \\
\text { leakage } \\
(\mu \mathrm{S})^{\mathrm{y}}\end{array}$ & $\begin{array}{l}\text { Symptom } \\
\text { bioassay }^{z}\end{array}$ \\
\hline \multirow[t]{2}{*}{ Methanol } & Precipitate & $32 \mathrm{~b}$ & 0 \\
\hline & Water fraction & $286 \mathrm{a}$ & 3.4 \\
\hline \multirow[t]{2}{*}{ Dialysis } & Fraction within dialysis tube & $24 \mathrm{~b}$ & 0 \\
\hline & Fraction outside dialysis tube & $305 \mathrm{a}$ & 3.6 \\
\hline \multirow[t]{2}{*}{ Activated charcoal } & Adsorbed fraction & $24 \mathrm{~b}$ & 0 \\
\hline & Nonadsorbed fraction & $318 \mathrm{a}$ & 3.6 \\
\hline \multirow[t]{2}{*}{ Ethyl acetate } & Solvent fraction & $35 \mathrm{~b}$ & 0 \\
\hline & Water fraction & $387 \mathrm{a}$ & 3.6 \\
\hline \multirow[t]{2}{*}{ Chloroform } & Solvent fraction & $25 \mathrm{~b}$ & 0 \\
\hline & Water fraction & $337 \mathrm{a}$ & 3.4 \\
\hline \multirow[t]{2}{*}{ Hexane } & Solvent fraction & $29 \mathrm{~b}$ & 0 \\
\hline & Water fraction & $334 \mathrm{a}$ & 3.6 \\
\hline \multirow[t]{2}{*}{ Carbon tetrachloride } & Solvent fraction & $31 \mathrm{~b}$ & 0 \\
\hline & Water fraction & $376 \mathrm{a}$ & 3.6 \\
\hline \multirow[t]{2}{*}{ Petroleum ether } & Solvent fraction & $40 \mathrm{~b}$ & 0 \\
\hline & Water fraction & $447 \mathrm{a}$ & 3.8 \\
\hline \multicolumn{4}{|l|}{ Noninoculated } \\
\hline Richard's medium & $\ldots$ & $32 \mathrm{~b}$ & 0 \\
\hline Water (control) & $\ldots$ & $21 \mathrm{~b}$ & 0 \\
\hline
\end{tabular}

y The data are the mean of six replications and the data followed by the same letter in a column are not significantly different from each other according to Duncan's multiple range test.

${ }^{\mathrm{z}}$ Intensity of the symptom was graded into five categories: $0=$ no symptoms; 1 to $4=1$ to $10 \%, 11$ to $25 \%, 26$ to $50 \%$, and 51 to $100 \%$ leaf sheath area affected, respectively. The data are the average of 25 leaf sheath samples. 
of crude toxin produced by each isolate was assessed by four independent experiments using 1 liter of medium each time. The detached leaf sheath bioassay was carried out with 25 replications. The electrolyte leakage bioassay was carried out with six replications. Conductance in microsiemens of the control leaves infiltrated with distilled water was subtracted from the conductance of the toxin-infiltrated leaves to determine the increase in electrolyte leakage by the toxin samples. The experiments were repeated once with similar results. The data were analyzed by DMRT.

Host specificity of the toxin. Host range of $R$. solani isolate $\mathrm{I}_{1}$ was tested by detached leaf bioassay. Leaves of rice cultivar IR 50, cotton (Gossypium hirsutum) cultivar MCU 5, tobacco (Nicotiana tabacum) cultivar VD 1, sapota (Achras sapota) cultivar Cricket Ball, and coconut (Cocos nucifera) cultivar VHC 2 were detached and used for the bioassay. While 4-cm pieces of rice and coconut were used, whole leaves of cotton, tomato, tobacco, and sapota were used for the bioassay. A 4-mm disc of the fungus $\left(\mathrm{I}_{1}\right)$ grown in PDA was placed at the middle of the leaf sample that was placed on a glass slide kept inside a petri dish lined with wet blotting paper. Development of the disease symptoms was assessed at 5 days after inoculation. The disease severity was graded into four categories depending upon size of the lesions on the leaf. Minimum concentration of the partially purified toxin (after passing through a Sephadex G-75 column) required to induce symptoms was assessed by making serial dilutions of a known quantity of the toxin. The experiments were carried out with 25 leaf samples for each test. The experiment was repeated twice with similar results.

Electrolyte leakage induced by toxin produced by $R$. solani isolate $\mathrm{I}_{1}$ in compatible (rice and cotton) and incompatible (sapota and coconut) hosts was assessed by infiltrating the partially purified toxin $(50 \mu \mathrm{l})$ into $100-\mathrm{mg}$ leaf samples (leaves cut into small pieces) in vacuo for $30 \mathrm{~min}$. The leaf sections were then rinsed with water, and $4 \mathrm{ml}$ of glass-distilled water was placed in each vial and inoculated on a reciprocal shaker (100 strokes per minute) at $25^{\circ} \mathrm{C}$. Conductances of ambient solutions were measured at intervals with an Orion model 120 conductivity meter. Conductance in microsiemens of the control leaves infiltrated with water was subtracted from the conductance of the toxin-infiltrated leaves to determine the increase in electrolyte leakage induced by toxin (33). There were six replications for each plant sample. Three independent experiments were conducted.

\section{RESULTS}

Isolation of toxin. A crude toxin that induced characteristic sheath blight symptoms in rice cultivars (Fig. 1) and electrolyte leakage from leaf sheath could be identified from $R$. solani isolate $\mathrm{I}_{1}$ grown in Richard's medium for 15 days by concentrating the culture filtrate in vacuo, adding methanol, removing precipitates by filtration, and removing methanol. A similar toxin could not be detected from noninoculated medium.

No toxin could be detected in the precipitates after adding methanol (Table 1). When the crude toxin preparation in water (after removal of methanol) was dialyzed using Sigma dialysis tubing (Sigma Chemical Co.) with exclusion at 12,000 molecular weight against distilled water at $4^{\circ} \mathrm{C}$ for $48 \mathrm{~h}$ and repeatedly changing the distilled water, the toxicity was completely lost, indicating that the toxin was a low molecular weight substance. When the crude toxin was treated with charcoal, the toxicity could be detected only in the filtrate, indicating that the toxin was not adsorbed by activated charcoal. When the crude toxin was partitioned with organic solvents like ethyl acetate, chloroform, hexane, carbon tetrachloride, and petroleum ether, the toxic component was always found in the water fraction (Table 1).

Partial purification of toxin. Effectiveness of each step of purification of the toxin is presented in Table 2. The fraction collected after Sephadex G-75 gel filtration was active even at $0.4 \mu \mathrm{l} / \mathrm{ml}$, and it was at least 3,500-fold more active than that obtained from culture filtrate and more than 300 -fold more active than the crude toxin obtained after methanol treatment (Table 2).

No phenylacetic acid derivatives or any phenolic compound could be detected in the partially purified toxin. The toxin obtained after gel filtration was found to contain carbohydrate and protein in the ratio of 40:1. The toxin activity was completely lost when it was treated with periodate. But when the toxin was treated

TABLE 2. Effectiveness of each step in the purification procedure in isolation of Rhizoctonia solani toxin

\begin{tabular}{lcc}
\hline Step in purification & $\begin{array}{c}\text { Dry weight } \\
(\mathrm{mg})^{\mathrm{y}}\end{array}$ & $\begin{array}{c}\text { Minimum concentration to } \\
\text { induce symptoms }(\mu \mathrm{g} / \mathrm{ml})^{\mathrm{z}}\end{array}$ \\
\hline Culture filtrate & 700 & 1,400 \\
Methanol treatment & 622 & 125 \\
Activated charcoal treatment & 356 & 50 \\
Ethyl acetate treatment & 292 & 3 \\
Sephadex G-75 gel filtration & 79 & 0.4
\end{tabular}

${ }^{x}$ Toxic chemical was obtained in the culture filtrate after evaporating to dryness; in the filtrate after methanol treatment discarding the residue; in the filtrate obtained after charcoal treatment; in the water fraction after partitioning with ethylacetate; and in the fraction after Sephadex G-75 gel filtration.

y Dry weight of the toxic chemical obtained per liter of the medium.

${ }^{\mathrm{z}}$ Minimum concentration of samples required to induce symptoms was determined by measuring the dilution end point.

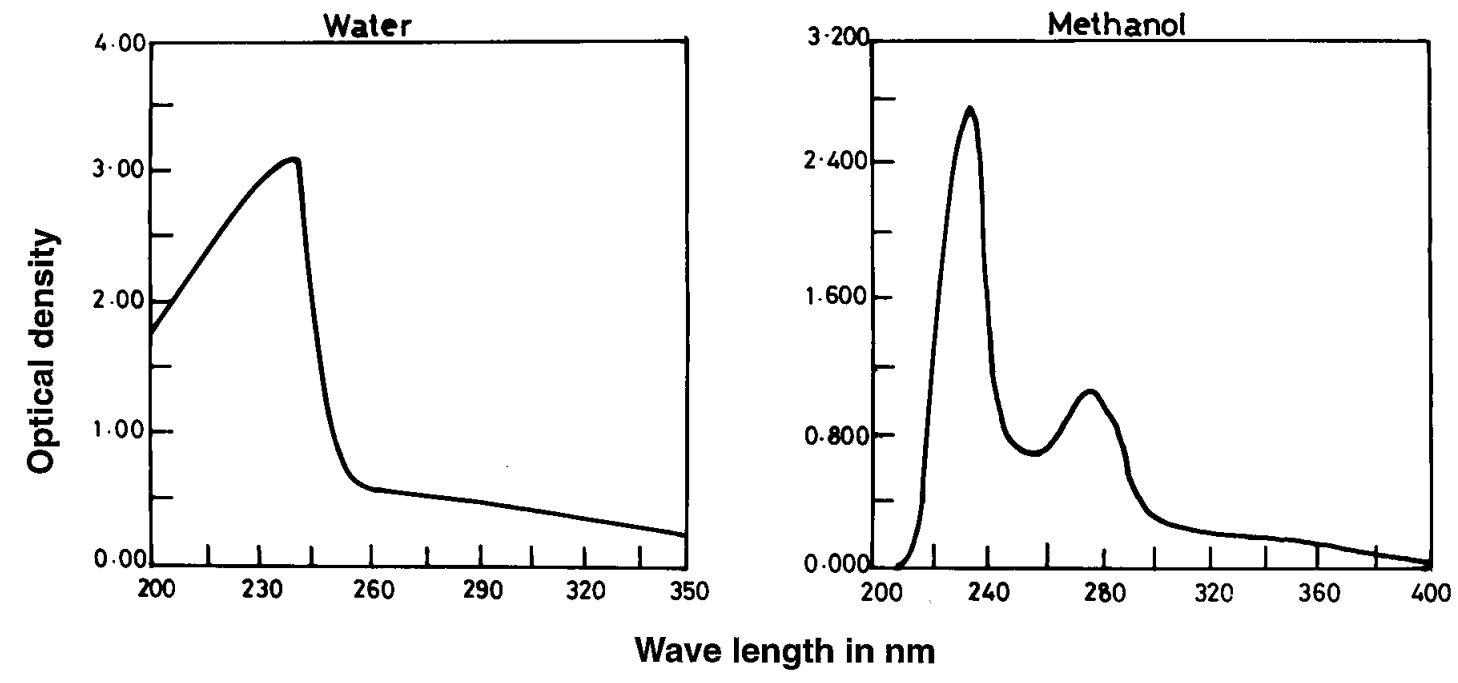

Fig. 2. Ultraviolet absorbance spectra of the toxin produced by Rhizoctonia solani. 
with proteinase $\mathrm{K}$, the activity was not lost. The results suggest that active component of the toxin was a carbohydrate. Gas-liquid chromatography of the carbohydrate showed that it contained glucose $(85 \%)$, mannose $(6 \%), N$-acetylgalactosamine $(6 \%)$, and $N$ acetylglucosamine $(3 \%)$. The toxin was thermostable and the toxicity was not lost even after autoclaving at $121^{\circ} \mathrm{C}$ for $20 \mathrm{~min}$.

The UV absorption spectrum of the toxin in methanol and water is presented in Figure 2. In methanol, the maximum absorbance was at $234 \mathrm{~nm}$, and in water, the maximum absorbance was at $244 \mathrm{~nm}$. The toxin could be isolated and purified from diseased leaves. The isolated toxin induced characteristic sheath blight symptoms on rice leaf sheath. It was identified as a carbohydrate, and its UV absorption spectrum was similar to that of toxin isolated in vitro.

Relationship between virulence and toxin production. Rice isolates differed in their virulence on rice cultivar IR 50. Both isolates $I_{1}$ and $I_{2}$ were highly virulent, while $I_{3}$ was moderately virulent and $\mathrm{I}_{4}$ was less virulent. The cotton isolate and the tomato isolate caused sheath blight symptoms in rice similar to the highly virulent rice isolates (Table 3).

All six isolates of $R$. solani produced the toxin. The partially purified toxins from all six isolates showed similar carbohydrate structure; in methanol, all of them showed maximum absorbance at $234 \mathrm{~nm}$, and in water, the maximum absorbance was at $244 \mathrm{~nm}$. The virulent isolates produced more toxin than the less virulent isolates (Table 3). This was indicated by the dilution end point of activity and electrolyte leakage bioassays and by the amount of toxin produced per liter of medium (Table 3).

TABLE 3. Relationship between virulence and toxin production by Rhizoctonia solani isolates

\begin{tabular}{|c|c|c|c|c|}
\hline Isolate & $\begin{array}{l}\text { Mean lesion } \\
\text { height }(\%)^{\mathrm{v}}\end{array}$ & $\begin{array}{l}\text { Dilution } \\
\text { end point }{ }^{\mathrm{w}}\end{array}$ & $\begin{array}{c}\text { Electrolyte } \\
\text { leakage }(\mu S)^{x}\end{array}$ & $\begin{array}{l}\text { Toxin produced } \\
(\mathrm{mg} / \text { /liter })^{\mathrm{y}}\end{array}$ \\
\hline \multicolumn{5}{|l|}{ Rice isolates } \\
\hline $\mathrm{I}_{1}$ & $78 \mathrm{a}^{\mathrm{z}}$ & $>1,000$ & $480 \mathrm{a}$ & $490 \mathrm{a}$ \\
\hline $\mathrm{I}_{2}$ & $70 \mathrm{a}$ & $>1,000$ & $390 \mathrm{a}$ & $500 \mathrm{a}$ \\
\hline $\mathrm{I}_{3}$ & $42 \mathrm{~b}$ & 100 & $260 \mathrm{~b}$ & $230 \mathrm{~b}$ \\
\hline $\mathrm{I}_{7}$ & $14 \mathrm{c}$ & 5 & $105 \mathrm{c}$ & $80 c$ \\
\hline Cotton isolate & $65 \mathrm{a}$ & $>1,000$ & $370 \mathrm{a}$ & $390 \mathrm{~b}$ \\
\hline Tomato isolate & $70 \mathrm{a}$ & $>1,000$ & $410 \mathrm{a}$ & $460 \mathrm{~b}$ \\
\hline
\end{tabular}

${ }^{v}$ Disease intensity was assessed by scoring tillers of all five plants in each replication grown under greenhouse conditions. There were four replications, and the mean value is presented.

${ }^{w}$ Dilution end point of activity of crude toxin. Mean of four independent experiments.

x Increase in electrolyte leakage over water control.

${ }^{y}$ Amount of toxin produced (mg/liter of medium).

${ }^{\mathrm{z}}$ Data followed by the same letter in a column are not significantly different from each other according to Duncan's multiple range test.

TABLE 4. Host range of Rhizoctonia solani isolate $\mathrm{I}_{1}$ and sensitivity of the hosts to its toxin ${ }^{\mathrm{w}}$

\begin{tabular}{lcc}
\hline Host & Disease intensity & $\begin{array}{c}\text { Toxin required to induce } \\
\text { symptoms }(\mu \mathrm{g} / \mathrm{ml})^{\mathrm{y}}\end{array}$ \\
\hline Rice & 3.8 & 0.5 \\
Cotton & 3.7 & 1.0 \\
Tomato & 3.8 & 1.0 \\
Tobacco & 2.1 & 10.0 \\
Sapota & 0.7 & 100.0 \\
Coconut & 0.0 & $\ldots{ }^{\mathrm{z}}$ \\
\hline
\end{tabular}

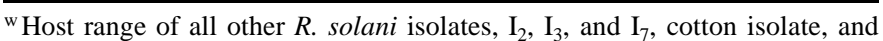
tomato isolate, and sensitivity of the hosts to the toxin produced by them were tested, and the results were similar to isolate $\mathrm{I}_{1}$.

${ }^{x}$ Disease intensity was assessed on detached leaves and graded into four categories ranging from 1 to 4 depending upon size of lesions. Where there was no symptom development it was scored as 0 . Twenty-five leaves were graded and the mean is presented.

y Minimum concentration of toxin required to induce symptoms $(\mu \mathrm{g} / \mathrm{ml})$.

${ }^{\mathrm{z}}$ No symptoms appeared at up to $5,000 \mu \mathrm{g} / \mathrm{ml}$ of toxin.
Host specificity of toxin. We tested more than 200 rice cultivars for their reaction to $R$. solani $\mathrm{I}_{1}$. All were susceptible to the fungus. The toxin $(10 \mu \mathrm{g} / \mathrm{ml})$ induced typical sheath blight symptoms in all rice cultivars tested. The pathogen had a wide host range, and from 300 host species screened, only two plant species (sapota and coconut) were not infected (data not shown). The host range of $R$. solani $\mathrm{I}_{1}$ was compared with the sensitivity of those hosts to the toxin produced by the fungus (Table 4). All plants that were susceptible to the fungus were also sensitive to the toxin, and the toxin induced typical lesions on the leaves even at a $0.5-$ to $10.0-\mu \mathrm{g} / \mathrm{ml}$ concentration. Sapota leaves were less susceptible to the fungus, and the toxin induced lesions on the leaves only at $100 \mu \mathrm{g} / \mathrm{ml}$ or more. Coconut leaves were immune to the fungus, and no lesions were induced by the toxin even when it was tested at $5,000 \mu \mathrm{g} / \mathrm{ml}$ (Table 4). The experiment was repeated with toxins produced by $R$. solani rice isolates $\mathrm{I}_{2}, \mathrm{I}_{3}$, and $\mathrm{I}_{7}$, and cotton and tomato isolates with similar results.

Toxin produced by $R$. solani $\mathrm{I}_{1}$ induced electrolyte leakage in leaves of rice and cotton (susceptible) and sapota (moderately resistant) and coconut (highly resistant) (Fig. 3). However, the toxin induced more leakage in susceptible hosts.

\section{DISCUSSION}

To prove the involvement of a toxin in disease development, the toxin should produce typical symptoms of the disease $(33,34)$, the toxin should exhibit the same host specificity as the pathogen (31), virulence of the pathogen should be correlated with the ability to produce the toxin (33), and the toxin should have been isolated from susceptible host plants after infection (10). Toxin produced by the rice sheath blight pathogen $R$. solani induced sheath blight symptoms that were indistinguishable from those induced by the fungus. All rice cultivars tested were susceptible to the pathogen. Major gene(s) giving complete or high resistance to this fungus have not been found, though extensive searches in rice germ plasm have been made (16). Only partial resistance to the disease has been reported $(4,11,38)$. Hence, specificity of the toxin could be demonstrated only by using hosts and nonhosts. The $R$. solani isolate from rice is reported to have a wide host range infecting plants belonging to more than 27 families inclusive of monocots and dicots (25). We could find only coconut leaves showing high resistance to the fungus, and sapota leaves showed moderate resistance. The toxin produced by the fungus did not produce any lesion on coconut leaves, and on sapota leaves, it could induce only slight lesion development. Thus, the toxin is host specific. Similar host specificity of toxin has bean demonstrated using nonhosts and hosts in Pyrenophora graminea (10), Septoria glycines (31), Pyrenophora teres (30), and Diaporthe phaseolorum var. caulivora (15). Virulence of $R$. solani isolates was correlated with the amount of toxin produced by each isolate, and the toxin was demonstrated to be in infected rice leaves. Thus, the toxin produced by the rice

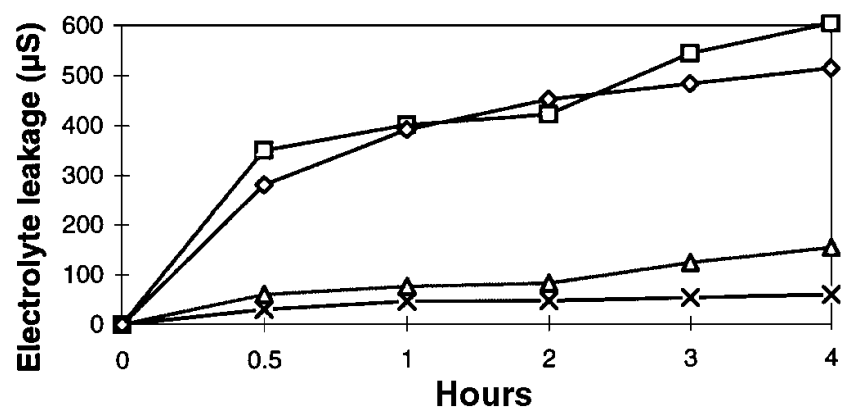

Fig. 3. Increase in electrolyte leakage caused by toxin produced by the Rhizoctonia solani $\mathrm{I}_{1}$ isolate in compatible (rice $-\square-$, cotton $-\diamond_{-}$) and incompatible (sapota $-\Delta-$, coconut $-\times-$ ) hosts. Least significant difference to compare any two means at $P=0.05$ is 65 . 
sheath blight pathogen $R$. solani satisfies all requirements to designate it as a host-specific toxin, and we would like to designate it as RS toxin.

The isolated toxin appears to be a carbohydrate. Toxins with a carbohydrate moiety have been reported to be produced by $P y$ renophora graminis (10), Septoria glycines (31), Fusarium solani (32), and Phytophthora spp. (37). Here, several $R$. solani isolates from rice, cotton, and tomato produced a similar carbohydrate toxin, and all of them induced sheath blight symptoms in rice. Isolates belonging to other anastomosis groups are also known to infect rice when inoculated under controlled conditions (25). Pathogenicity and virulence of different anastomosis groups of $R$. solani are not host specific (2), and overlapping of host or host range in various anastomosis groups is common (36). Several toxic metabolites such as phenylacetic acid and its derivatives have been isolated from culture filtrates of various $R$. solani isolates including those isolated from rice $(1,12)$, but their role in rice sheath blight disease development has not been established. The current studies have provided evidence for production of a carbohydrate toxin by $R$. solani and its involvement in the development of the rice sheath blight disease in rice. The detection of a toxin, which is involved in disease development, from $R$. solani, a pathogen that affects many major crops of the world, will aid in studies on etiology and disease resistance mechanisms against the pathogen. The toxin may be useful for in vitro selection, since callus with resistance to toxins produced by these pathogens on regeneration are likely to produce resistant plant material (35). The toxin may also be useful to identify detoxification genes from plants and microbes. These genes could be exploited to develop transgenic disease-resistant plants. These lines of investigation are in progress in our laboratory.

\section{ACKNOWLEDGMENTS}

This work was supported, in part, by a grant from the Rockefeller Foundation, United States.

\section{LITERATURE CITED}

1. Akoi, H., Sassa, T., and Tamura, T. 1963. Phytotoxic metabolites of Rhizoctonia solani. Nature 200:575.

2. Anderson, N. A. 1982. The genetics and pathology of Rhizoctonia solani. Annu. Rev. Phytopathol. 20:329-347.

3. Ashwell, G. 1966. New colorimetric methods of sugar analysis. Methods Enzymol. 8:85-94.

4. Bonman, J. M., Ghush, G. S., and Nelson, R. J. 1992. Breeding rice for resistance to pests. Annu. Rev. Phytopathol. 30:507-528.

5. Boosalis, M. G. 1950. Studies on the parasitism of Rhizoctonia solani Kuehn on soybeans. Phytopathology 40:820-831.

6. Bradford, M. M. 1976. A rapid and sensitivity method for the quantification of microgram quantities of protein utilizing the principles of protein dye binding. Anal. Biochem. 72:248-257.

7. Chen, Y. 1958. Studies on metabolic products of Hypochnus sasakii Shirai. Isolation of $p$-hydroxyphenylacetic acid and its physiological activity. Bull. Agric. Chem. Soc. Jpn. 22:136-142.

8. DeWit, P. J. G. M., and Roseboom, P. H. M. 1980. Isolation, partial characterization and specificity of glycoprotein elicitors from culture filtrates, mycelium and cell walls of Cladosporium fulvum. Physiol. Plant Pathol. 16:391-408.

9. Frank, J. A., and Francis, S. K. 1976. The effect of a Rhizoctonia solani phytotoxin on potatoes. Can. J. Bot. 54:2536-2540.

10. Haegi, A., and Porta-Puglia, A. 1995. Purification and partial characterization of a toxic compound produced by Pyrenophora graminea. Physiol. Mol. Plant Pathol. 46:429-444.

11. Hashioka, Y. 1991. Inheritance of resistance to sheath blight in rice varieties. Ann. Phytopathol. Soc. Jpn. 15:21-26.

12. Iacobellis, N. S., and DeVay, J. E. 1987. Studies on pathogenesis of Rhizoctonia solani in beans: An evaluation of the possible role of phenylacetic acid and its hydroxy derivatives as phytotoxins. Physiol. Plant
Pathol. 30:421-432.

13. Kohmoto, K., Fukui, R., Mizuno, M., and Nishimura, S. 1973. Pathochemical studies on Rhizoctonia disease. III. Characteristic production of Rhizoctonia toxins and their vivo toxicity. J. Fac. Agric. Tottori Univ. 8: 21-31.

14. Kohmoto, K., and Nishimura, S. 1974. Pathochemical studies on Rhizoctonia disease. II. Substrate specificity in specific meta-hydroxylation of aromatic acids by Rhizoctonia solani Kühn. Ann. Phytopathol. Soc. Jpn. 40:78-85.

15. Lalitha, B., Snow, J. P., and Berggren, G. T. 1989. Phytotoxin production by Diaporthe phaseolorum var. caulivora, the causal organism of stem canker of soybean. Phytopathology 79:499-504.

16. Li, Z., Pinson, S. R. M., Marchetti, M. A., Stansel, J. W., and Park, W. D. 1995. Characterization of quantitative trait loci (QTLs) in cultivated rice contributing to field resistance to sheath blight (Rhizoctonia solani). Theor. Appl. Genet. 91:382-388.

17. Mandava, N. B., Orellana, R. G., Warthen, J. D., Worley, J. F., Dutky, S. R., Finegold, H., and Weathington, B. C. 1980. Phytotoxins in Rhizoctonia solani, isolation and biological activity of $m$-hydroxy and $m$ methoxy phenylacetic acids. J. Agric. Food Chem. 28:71-75.

18. Mawhinney, T. P. 1986. The simultaneous determination of $N$-acetylglucosamine, $\mathrm{N}$-acetylgalactosamine, $\mathrm{N}$-acetylglucosaminitol, and $\mathrm{N}$-acetylgalactosaminitol by gas-liquid chromatography. J. Chromatogr. 351:91-102.

19. Mawhinney, T. P., Feather, M. S., Barberc, G. J., and Martinez, J. R. 1980. The rapid, quantitative determination of neutral sugars and amino sugars in glycoproteins by gas-liquid chromatography. Anal. Biochem. 101:112-117.

20. Mew, T. W., and Rosales, A. M. 1986. Bacterization of rice plants for control of sheath blight caused by Rhizoctonia solani. Phytopathology 76:1260-1264.

21. Newton, W., and Mayers, N. 1935. The physiology of Rhizoctonia solani Kühn. IV. The effect of a toxic substance produced by Rhizoctonia solani Kühn when grown in liquid culture, on the growth of wheat, carrots, and turnips. Sci. Agric. 15:399-401.

22. Nishimura, S., and Sasaki, M. 1963. Isolation of the phytotoxic metabolites of Pellicularia filamentosa. Ann. Phytopathol. Soc. Jpn. 28:228-234.

23. Nourel Dein, M. S., and Sharkas, M. S. 1964. Association of a toxic substance from the culture filtrate of Rhizoctonia solani. Phytopathol. Z. 52:55-58.

24. O'Neill, N. R. 1976. Etiological aspects of foliar blights of rice, soybean, and sorghum caused by Rhizoctonia sp. Ph.D. dissertation. Louisiana State University, Baton Rouge.

25. Premalatha Dath, A. 1990. Sheath Blight Disease of Rice and Its Management. Associated Publishing Company, New Delhi, India.

26. Roy, A. K. 1993. Sheath blight of rice. Indian Phytopathol. 46:197-205.

27. Sharma, N. R., Teng, P. S., and Olivares, F. M. 1990. Comparison of assessment methods for rice sheath blight disease. Philipp. Phytopathol. 26:20-24.

28. Sherwood, R. T. 1965. Phytotoxin. U.S. patent 3,179,653.

29. Sherwood, R. T., and Lindberg, C. G. 1962. Production of a phytotoxin by Rhizoctonia solani. Phytopathology 52:586-587.

30. Smedegard-Petersen, V. 1977. Isolation of two toxins produced by $P y-$ renophora teres and their significance in disease development of netspot blotch of barley. Physiol. Plant Pathol. 10:203-211.

31. Song, H. S., Lim, S. M., and Clark, J. M., Jr. 1993. Purification and partial characterization of a host-specific pathotoxin from culture filtrates of Septoria glycines. Phytopathology 83:659-661.

32. Thomas, C. A. 1949. A wilt-inducing polysaccharide from Fusarium solani f. eumartii. Phytopathology 39:572-579.

33. Vidhyasekaran, P., Borromeo, E. S., and Mew, T. W. 1986. Host-specific toxin production by Helminthosporium oryzae. Phytopathology 76:261-266.

34. Vidhyasekaran, P., Borromeo, E. S., and Mew, T. W. 1992. Helminthosporium oryzae toxin suppresses phenol metabolism in rice plants and aids pathogen colonization. Physiol. Mol. Plant Pathol. 41:307-315.

35. Vidhyasekaran, P., Ling, D. H., Borromeo, E. S., Zapata, F. J., and Mew, T. W. 1990. Selection of brown spot-resistant rice plants from Helminthosporium oryzae toxin-resistant calluses. Ann. Appl. Biol. 117:515-523.

36. Weinhold, A. R. 1977. Population of Rhizoctonia solani in agricultural soils determined by a screening procedure. Phytopathology 67:566-569.

37. Woodward, J. R., Keane, P. S., and Stone, B. A. 1980. Structures and properties of wilt-inducing polysaccharides from Phytophthora spp. Physiol. Plant Pathol. 16:439-454.

38. Xie, Q. J., Linscombe, S. D., Rush, M. C., and Jodari-karimi, F. 1992. Registration of LSBR-33 and LSBR-5 sheath blight resistant germplasm lines of rice. Crop Sci. 32:507. 